\title{
Os entroncamentos entre política e lazer na experiência do Círculo de Estudos Sociais Francisco Ferrer $(1910-1915) .1$
}

Bruno Caccavelli

Resumo: O objetivo deste texto é evidenciar os entroncamentos entre as atividades políticas e de lazer através da análise das experiências do Círculo de Estudos Sociais Francisco Ferrer, observando as múltiplas práticas empregadas pelo grupo sobre a organização dos trabalhadores e também marcando a importância dos momentos de lazer e diversão vividos nos espaços associativos para o processo formativo da classe operária.

Palavras-chave: Associações; Lazer; Trabalhadores.

\section{Apresentação}

Os trabalhadores, já sabemos, tornaram-se uma força significativa na cidade de São Paulo nos fins do século XIX.3 Desde cedo, constituíram associações de vários tipos e com diversas finalidades - mutualistas, sindicais, recreativas. As diversas correntes do movimento operário, nunca sem dificuldades, se empenhavam na organização, mobilização, proteção e luta dos trabalhadores em suas sociedades. Todavia, devemos levar em conta uma outra dimensão da atuação dessas associações. Grande parte das atividades eram direcionadas à sensibilização e aprofundamento cultural dos trabalhadores, uma necessidade que se traduzia em múltiplas intervenções, incluindo a própria luta pela redução da jornada de trabalho que visava ao maior tempo livre. Dentre os instrumentos de que lançavam mão, o teatro certamente representava o mais

\footnotetext{
${ }^{1}$ Artigo resultante da dissertação de mestrado desenvolvida sob o apoio financeiro da FAPESP. 2 Mestre em História pela Universidade Federal de São Paulo e Especialização em História pela Pontifícia Universidade Católica de São Paulo. Email: bcaccavelli@gmail.com

3 HALL, Michael. "O Movimento Operário na Cidade de São Paulo: 1890-1954". In: PORTA, Paula (org.). História da Cidade de São Paulo: a cidade na primeira metade do século XX. (v. 3). São Paulo: Paz e Terra, 2004, p. 259.
} 
importante, em que podiam abordar temáticas sociais como a miséria, a exploração do trabalho, denúncias de injustiças. Contudo, nem sempre as peças teatrais cumpriam com as exigências de uma educação estritamente política. Em muitos casos, eram apenas um componente das festas cujos programas previam ainda quermesses e bailes. 4

Atividades como festas e bailes eram motivo de grandes divergências entre as diferentes correntes do movimento operário. Entre os anarquistas, sobretudo, eram, em alguns casos, considerados desperdício de energia ou algo útil apenas como propaganda. Em associações ligadas a outros grupos, porém, esses eventos eram mais comuns e convites eram feitos para que os trabalhadores aproveitassem os momentos de diversão para descansar e revigorar as forças para as lutas. Isso não significa dizer, entretanto, que as atividades eram organizadas como meras ocasiões de distração. Ao contrário, muitas vezes eram planejadas com finalidades mais concretas, como coleta de fundos para financiar jornais, greves, criar caixas de resistência, ajudar companheiros presos ou exilados, órfãos e viúvas, e abrir bibliotecas. Assim, a mistura de práticas políticas com outras tais como rifas e bailes, apresentavam-se também como uma estratégia de se infiltrar nas classes populares e garantir a participação dos trabalhadores. 5

$\mathrm{O}$ foco deste trabalho recai sobre os entroncamentos entre atividades políticas e de lazer e a sua importância no processo formativo da classe operária. Mesmo tendo em mente a grande diversidade de associações, o que deve nos afastar de generalizações, algumas atividades eram comuns à grande parte delas. Para entender melhor as articulações entre as diversas práticas, proponho acompanhar um grupo em particular, o Círculo de Estudos Sociais Francisco Ferrer, que atuou entre 1910 e 1915 nos bairros paulistanos do Brás e da Mooca, mas sobretudo neste último em que era a única associação de caráter mais político no período, servindo ainda, entre comícios, palestras e festas, de abrigo societário a trabalhadores ligados às diferentes correntes

\footnotetext{
4 TRENTO, Angelo. "Organização Operária e Organização do Tempo Livre entre os Imigrantes Italianos em São Paulo". In: CARN EIRO, Maria L. T. et. al. (org.). História do Trabalho e História das migrações: Trabalhadores Italianos e Sindicatos no Brasil (Séculos XIX e XX). São Paulo: Edusp: Fapesp, 2010, p. 239240.

5 TOLEDO, Edilene. Travessias Revolucionárias: idéias e militantes sindicalistas em São Paulo e na Itália (1890-1945). Campinas-SP: Editora da Unicamp, 2004, p. 184, 247 e 289.
} 
do movimento operário. Assim, busquei construir uma narrativa que não dividisse em blocos distintos as atividades, mas que mantivesse uma certa ordem cronológica dos eventos, procurando perceber como a associação atuava, misturando a dimensão de luta e o lazer.

\section{O Círculo de Estudos Sociais Francisco Ferrer: seu funcionamento, seus participantes}

Fundado em 1910 no bairro do Brás, o Círculo de Estudos Sociais Francisco Ferrer nasceu "(...) com o fim de divulgar na classe trabalhadora o estudo da questão social em seus diversos aspectos (...)" ${ }^{6} \mathrm{~A}$ primeira reunião ocorreu na sede situada à rua Martim Burchard, n. ${ }^{0}$ 11, às sete e meia da noite de 6 de junho. Naquele mesmo ano, o grupo passou por outros endereços: rua Saião Lobato, n. $^{0}$ 28; rua do Gasômetro, n. ${ }^{\circ} 159$; rua Monsenhor Anacleto, $n .^{\circ} 38$; voltando a ocupar o número 11 da rua Martim Burchard em outubro. 7

Entre os seus organizadores destacavam-se Angelo Scala e Francisco Calvo. Scala, operário mecânico e italiano, era autor do folheto editado pelo grupo, chamado Morale e Religione, em que "(...) procura propagar, em forma muito simples, o ideal de emancipação econômica do operariado". ${ }^{8}$ Nascido em San Rufo, na Campânia, Angelo era filho de Antonio Scala e Maria Rosa Fanelli, camponeses em sua terra natal. Imigrou para o Brasil ainda muito jovem, com seus pais e o irmão Giovanni, por volta de 1897. Em São Paulo, ao lado do irmão, participou de forma intensa do movimento operário. Frequentou as reuniões da Federação Operária de São Paulo9 e foi, junto com o irmão e com Giulio Sorelli, um dos líderes dos esforços para a organização sindical dos trabalhadores. ${ }^{10}$

Francisco Calvo, espanhol, era operário sapateiro empregado na fábrica de calçados Clark, na Mooca, bairro em que mantinha a sua residência na rua da Mooca,

\footnotetext{
6 A Lanterna, 25/11/1911.

7 Fanfulla, 01/06/1910, 03/06/1910, 12/06/1910, 19/06/1910 e 24/10/1910, respectivamente.

${ }^{8}$ A Lanterna, 18/11/1911 e 02/09/1911.

9 TOLEDO, Edilene. "Imigração, Sindicalismo Revolucionário e Fascismo na Trajetória do Militante Italiano Edmondo Rossoni". Cadernos AEL, Campinas/IFCH/AEL, v. 15, n. 27, 2009, p. 135.

10 BIONDI, Luigi. Classe e Nação: trabalhadores e socialistas italianos em São Paulo (1890-1920).

Campinas-SP: Editora da Unicamp, 2011, p. 289.
} 
n. ${ }^{\circ}$ 154. Calvo se empenhou fortemente na organização dos trabalhadores de seu ofício, a União Geral dos Sapateiros, da qual se tornou, mais tarde, em 1912, o secretário. ${ }^{11}$

O CES Francisco Ferrer realizava assembleias abertas a “(...) companheiros não inscritos", provavelmente em uma tentativa de conseguir filiados a quem pudessem difundir os seus ideais e que contribuíssem, também financeiramente, com a existência da associação. Geralmente, esses eventos seguiam um mesmo programa, que contava com leituras de atas, balanço do caixa social, discussão sobre o movimento interno, palestras, aulas, comemorações ${ }^{12}$ e eleições para a atribuição de cargos em comissões com diversas finalidades. ${ }^{13}$

O grupo era dirigido por uma comissão administrativa - em 1911, composta, além de Scala e Calvo, por Giovanni Giacobbe, Jannicelli D’Alfonso e Lorenzo Basso ${ }^{14}$ -, algo mais simples do que as diretorias elaboradas que contavam com presidente e vice, tesoureiros e conselhos fiscais, encontradas em outras associações, sobretudo nas mutualistas. Esse caráter organizativo mais informal remete às concepções dos grupos identificados com o sindicalismo revolucionário ${ }^{15}$, o que é revelador do modo como pensavam os seus associados. ${ }^{16}$

O CES Francisco Ferrer estava inserido nas lutas e manifestações que ocorriam entre os grupos operários. Em outubro de 1911, partiu exatamente da sua sede o grande comício que lembrava a morte do pedagogo libertário Francisco Ferrer y Guardia, a quem o grupo prestou homenagem já em sua nomenclatura. A partir daquele local, muitos manifestantes tomaram as ruas do Brás, “(...) com a banda de música à frente”, caminhando em direção ao largo da Concórdia, local em que, (...) perante uma grande massa de povo, falaram do coreto Leão Aymoré e A. Scala, pondo-se depois a coluna em marcha para o largo de S. Francisco". ${ }^{17}$

\footnotetext{
11 A Lanterna, 25/11/1911 e 25/05/1912.

12 Fanfulla, 06/06/1910 e 28/08/1911.

${ }^{13}$ Ver também, como exemplo, as edições do Fanfulla de 06/06/1910, 28/08/1911 e 25/11/1912.

14 Fanfulla, 19/11/1911.

${ }^{15}$ BATALHA, Claudio H. M. "Cultura associativa no Rio de Janeiro da Primeira República". In: BATALHA, Claudio H. M. et. al. (Org.). Cultura de Classes: identidade e diversidade na formação do operariado. Campinas-SP: Editora Unicamp, 2004, p. 100.

${ }^{16}$ TOLEDO, Edilene. Travessias Revolucionárias: idéias e militantes sindicalistas em São Paulo e na Itália (1890-1945). Campinas-SP: Editora da Unicamp, 2004, p. 274-276.

${ }^{17}$ A Lanterna, 21/10/1911.
} 
Com o grande número de pessoas, os discursos inflamados lograram sucesso. Animados, os organizadores marcaram um novo comício para o mês de novembro, “(...) para comemorar os mártires de Chicago e lançar-se um protesto contra as guerras”. Contudo, “(...) apesar de seus fins serem claramente conhecidos, a reunião não pôde realizar-se por proibição da polícia, que lhe atribuiu falsamente outros intuitos". A acusação era de que a manifestação teria por fim difamar o rei da Itália.

De toda forma, as tentativas de coibir as manifestações por parte dos poderes públicos não se restringiam à proibição. No dia anterior à manifestação, 10 de novembro, quando estavam reunidos muitos sócios para as preparações de outro evento, que ocorreria ainda naquele mês, a sede do CES Francisco Ferrer foi assaltada pela polícia, que, “(...) com os seus agentes e soldados de revólver em punho”, prendeu vinte e duas pessoas. Alguns dos sócios foram liberados dois dias depois. Calvo e Scala, “(...) apesar dos numerosos habeas-corpus requeridos e prejudicados pela astucia da polícia”, só conseguiram a liberdade seis dias depois, em uma quinta-feira, 16 de novembro. ${ }^{18}$

O evento trágico na sede, contudo, não impediu que prosseguissem os planos feitos na reunião. Em 18 de novembro, um sábado, os sócios realizaram a planejada festa de propaganda. Calvo e Scala, possivelmente como uma maneira de demonstrar a sua resistência frente às ações repressivas da polícia, participaram da velada, que foi realizada às oito e meia da noite, no salão Germânia. O programa da festa era o seguinte:

$1^{\mathrm{a}}$ parte - Representação da peça em 2 atos, de Pedro Gori, Senza Patria; $2^{\mathrm{a}}$ parte - Conferência; $3^{\mathrm{a}}$ parte - Representação de uma comedia em um ato; $4^{\mathrm{a}}$ parte - Recitativo do monólogo napolitano Il Cafone. Terminará a festa com um baile familiar. ${ }^{19}$

No dia seguinte, o jornal Fanfulla apresentava os frutos do evento:

As senhoras M. Barbieri, A. Fabbri, T. Camilli e os senhores G. Turola, A. Vergani, A. Avallone, T. Gesmaro, G. Panighelli, E. Fagiano e V. Richetti,

\footnotetext{
${ }^{18}$ A Lanterna, 18/11/1911.

${ }^{19}$ A Lanterna, 18/11/1911.
} 
intérpretes da amostra em dois atos 'Senza Patria' e uma farsa, foram muito aplaudidos. Também o senhor Giuseppe Cocciolito foi aclamado no monólogo 'Il cafone' ou 'La festa di S. Antimo'. Em um interlúdio os senhores Angelo Scala e Francisco Calvo falaram sobre o anticlericalismo, sendo aplaudidos. ${ }^{20}$

Das representações teatrais contidas no programa, certamente o título de maior importância para os valores operários era a obra Senza Patria de Pietro Gori, este autor bastante conhecido entre os trabalhadores. Aliando-se ao drama de Gori, o tema da conferência - $o$ anticlericalismo - atribuía ao evento um caráter sobretudo militante, que ultrapassava o intuito do mero passatempo insinuado pela presença da comédia e do baile. A presença desses últimos elementos no programa, contudo, não deixa de ser relevante. Apesar das duras críticas que se viam na imprensa operária sobre as obras que não ofereciam uma relação direta com a realidade social21, não era incomum que associações de caráter mais político utilizassem a comédia em suas festas, porém sempre com o intuito de levar os espectadores à reflexão, conscientizar sobre a degradação moral, desmistificar o dinheiro e criticar a cobiça material, reforçando um sentido pedagógico nas apresentações. ${ }^{22}$

Nas associações de trabalhadores, era comum que os atores fossem todos amadores, e igualmente ocorria no CES Francisco Ferrer. Além disso, ao cruzarmos as informações sobre os nomes que aparecem no programa da festa, percebemos que os atores muitas vezes traziam para o grupo experiências prévias de palco em outras sociedades. Angelina Fabbri, até ao menos 1909, integrava o corpo cênico do Círcolo Ricreativo Tina di Lorenzo, esta associação que representava dramas populares e comédias no idioma italiano ${ }^{23}$, buscando reforçar uma identidade de marca étnica, o que é indicado ainda na homenagem à atriz nascida em Turim. Giuseppe Turola, era, em 1910, diretor cênico do Círcolo Matteo Renato Imbriani²4, associação que

\footnotetext{
${ }^{20}$ Fanfulla, 19/11/1911.

21 TRENTO, Angelo. "Organização Operária e Organização do Tempo Livre entre os Imigrantes Italianos em São Paulo". In: CARNEIRO, Maria L. T. et. al. (org.), História do Trabalho e História das migrações: Trabalhadores Italianos e Sindicatos no Brasil (Séculos XIX e XX). São Paulo: Edusp: Fapesp, 2010, p. 244247.

22 PRADO, Antônio. Trincheira, Palco e Letras. Crítica, literatura e utopia no Brasil. São Paulo: Cosac \& Naify, 2004, p. 119.

${ }^{23}$ Fanfulla, 12/02/1909.

${ }^{24}$ A Lanterna, 17/12/1910.
} 
homenageou uma figura proeminente nascida na região da Campânia. Este último caso, contudo, sugere um tipo de entroncamento identitário - já que Imbriani integrou o movimento irredentista que tinha por objetivo a unificação das regiões sob domínio da Áustria à Itália -, ao mesmo tempo marcando uma posição republicana, reforçando um sentimento regional e sinalizando uma abertura para italianos provenientes das diversas regiões. ${ }^{25}$

Como os sobrenomes indicam, os atores eram todos italianos, algo que se refletia no idioma em que apresentaram os títulos teatrais. Mesmo que as atividades do CES Francisco Ferrer não apresentassem indícios de que a etnia fosse um requisito para se associar - ao contrário, a atuação do grupo marcou por diversas vezes um caráter fortemente internacionalista -, essa característica estava presente de maneira relevante, reforçando a ideia de que o sentimento de pertencimento étnico e de classe não eram incompatíveis. ${ }^{26}$ Assim, além da dinâmica interassociativa que se desenvolvia, parece bastante claro que, frente a essas múltiplas identidades, ainda mais se tivermos em conta que no mesmo período de existência do CES Francisco Ferrer havia outras associações dramáticas de que podiam participar, emergia entre estes atores uma consciência de classe declarada na opção em tomar parte de um grupo engajado na organização dos trabalhadores, que promovia peças teatrais em que pudessem não apenas atuar, mas que também refletiam suas escolhas e valores bastante coletivistas e críticos à sociedade burguesa. ${ }^{27}$

A nota sobre os resultados da festa mostrava ainda uma longa lista com os nomes dos presentes, e é possível perceber pelos sobrenomes uma maioria de participantes italianos, o que se aproximava da composição do corpo cênico da sociedade. Mas é preciso notar que ali também figuravam sobrenomes que indicam origem espanhola, portuguesa ou brasileira - alguns são os de Antonio de Oliveira, Martina de Oliveira, Manoel da Silva, Cesarina Rosário, Alyra Lopez, Fernanda da Rocha -, reforçando o internacionalismo no seio da associação.

25 BIONDI, Luigi. Classe e Nação: trabalhadores e socialistas italianos em São Paulo (1890-1920). Campinas-SP: Editora da Unicamp, 2011, p. 71.

${ }^{26}$ Ver BIONDI, Luigi. Classe e Nação: trabalhadores e socialistas italianos em São Paulo (1890-1920). Campinas-SP: Editora da Unicamp, 2011.

${ }^{27}$ THOMPSON, Edward. A Formação da Classe Operária Inglesa. v. 2. Rio de Janeiro: Paz e Terra, 1987, p. 316. 
Um outro fator que chama atenção na lista é a grande recorrência de sobrenomes. Compareceram à festa Gloria, Narciso e Nensio Bellini; Domenico, Francesco e Giulio Biamini; Adelina, Carlo, Carmela, Francesco e Ida Blasiferri; Alfonso, Caterina e Laura DeVivo; Carmela, Madalena e Raffaele Del Vecchio; Cicceta, Gina e Giovanni Giacobbe; Americo, Elvira, Giuseppe, Italia, Rosa e Santa Stella, para ficar em alguns exemplos. Essa concentração indica que os trabalhadores compareciam a estes eventos em família, uma instituição de posição central na vida emocional e no cotidiano dos imigrantes ${ }^{28}$, mas que também se punha em acordo com uma prática bastante difundida entre militantes das diferentes correntes do movimento operário, sobretudo anarquistas, que a entendiam não como a base da propriedade privada, mas como o ambiente privilegiado para a propagação de seus valores. 29

A listagem permite ainda perceber a mobilidade na sociabilidade dos trabalhadores e diversas interconexões associativas, já que alguns dos presentes na festa participavam de outras associações. Vincenzo Amodio fazia parte da comissão da União Gráfica de São Paulo; Palmiro Grassini era conselheiro da Liga dos Pedreiros; Antonio de Oliveira era representante do Sindicato dos Metalúrgicos.30 A presença desses trabalhadores demonstra que as identidades que se constituíam dentro do CES Francisco Ferrer ultrapassavam a de ofício, sugerindo uma identificação mais abrangente, de classe. Outros nomes que constam na lista parecem confirmar esta idéia, indicando que a sociedade não estava fechada à presença de trabalhadores ligados a uma ou outra corrente. Por exemplo, a presença de Giovanni Scala, irmão de Angelo e socialista conhecido, é um indício de que militantes das mais diversas correntes do movimento operário frequentavam os mesmos espaços, levando para aqueles ambientes as suas idéias, os seus valores, as obras de sua predileção, sugerindo

\footnotetext{
${ }^{28}$ HALL, Michael. "Imigrantes na cidade de São Paulo". In: PORTA, Paula (org.). História da Cidade de São Paulo: a cidade na primeira metade do século XX. (v. 3). São Paulo: Paz e Terra, 2004, p. 142.

${ }^{29}$ CABRAL. Michelle N. Teatro Anarquista, Futebol e Propaganda: tensões e contradições no âmbito do lazer. Dissertação de Mestrado. Universidade Federal do Rio de Janeiro, UFRJ: Rio de Janeiro, 2008, p. 61.

30 Ver HALL, Michael; PINHEIRO, Paulo (Org.). A Classe Operária no Brasil. 1899-1930. Documentos. v. 1. Alfa-Ômega: São Paulo, 1979, p. 74 e 160; BIONDI, Luigi. Entre associações étnicas e de classe: os processos de organização política e sindical dos trabalhadores italianos na cidade de São Paulo (18901920). Tese de doutorado. Universidade Estadual de Campinas, Unicamp: Campinas-SP: 2002, p. 277.
} 
ao mesmo tempo certa relação dos sócios do CES Francisco Ferrer com as idéias do sindicalismo revolucionário, corrente que, não raro, recebia militantes anarquistas e socialistas, propondo a neutralidade política, funcionando na verdade como ponto de aglutinação entre as diversas correntes. ${ }^{31}$

\section{As dificuldades e os esforços de reconstituição}

O sucesso da festa, todavia, não aliviou as dificuldades que o grupo encontrou após a invasão da sede. Era preciso encontrar um novo local em que pudessem preparar e realizar suas atividades, e isso para a própria continuidade da associação. Calvo ofereceu a sua residência na rua da Mooca, $n .^{\circ}$ 154, como endereço provisório de correspondência e reuniões. Poucos dias depois, publicaram no jornal A Lanterna um pedido “(...) a todos os grupos editores de livros, folhetos, revistas e jornais para que lhe enviem exemplares das suas publicações”. Esse esforço de reconstituição da biblioteca indica que no dia da invasão as ações não se limitaram à prisão dos presentes, mas passaram além disso pela destruição do material que se encontrava no local. Além disso, significava a retomada da atuação e a reinserção do grupo em uma rede de associações, como explicita o restante da nota: “(...) desejando também travar relações com as agrupações avançadas de toda a parte, pede às mesmas lhe comuniquem as suas iniciativas". 32

A comissão administrativa, em dezembro de 1911, fez “(...) um caloroso apelo a todos os seus associados, convidando-os a voltar à atividade indispensável para a continuação da sua obra de educação e propaganda social no seio da classe operária”. Afirmavam ainda a vontade de manter as costumeiras reuniões “(...) nas quais alguns companheiros fazem sempre palestras sobre a questão social e sobre noções de ensino prático".33

Os esforços, tudo indica, tiveram resultados positivos. Em fevereiro de 1912, o CES Francisco Ferrer anunciou a sua mudança definitiva para a nova sede, à “(...) rua

\footnotetext{
31 TOLEDO, Edilene. Travessias Revolucionárias: idéias e militantes sindicalistas em São Paulo e na Itália (1890-1945). Campinas-SP: Editora da Unicamp, 2004, p. 41 e 213.

32 A Lanterna, 25/11/1911.

33 A Lanterna, 23/12/1911.
} 
da Mooca, n. ${ }^{\circ}$ 132, onde tem a sua sala de leitura à disposição das pessoas que a queiram frequentar”, mantendo ainda os pedidos “(...) a todos os grupos editores” para o envio de exemplares “(...) de suas publicações de propaganda (...)”.34 Naquele período, muitos esforços eram feitos por toda a cidade para reavivar o sindicalismo revolucionário35, e na Mooca esse empenho ocorria em grande medida na sede do Círculo. Em março de 1912, os sapateiros utilizaram a sede tentando se organizar em torno da criação de um sindicato.

\begin{abstract}
Aos operários sapateiros e afins.
Todos os trabalhadores da classe estão convidados para duas assembleias que ocorrerão esta manhã, às 8 na rua da Mooca, 132 e na rua S. Domingos, 25. Estas assembleias serão realizadas nestes dois locais diversos por comodidade dos operários da classe que participarão daquele que lhes for mais conveniente. Em ambas as reuniões se discutirá sobre a organização de um sindicato (...).
\end{abstract}

A Comissão Provisória. ${ }^{36}$

Os sapateiros voltaram à sede do CES Francisco Ferrer, e, em maio, já funcionava a União dos Sapateiros, cujo secretário era Francisco Calvo. 37 Os pedreiros e serventes, que trabalhavam "(...) pela constituição de uma sociedade de resistência da sua classe", realizando diversas reuniões pela cidade, também se reuniram no local. $\mathrm{E}$ os alfaiates, em seguida, utilizaram o espaço para discutir a “(...) fundação de uma agremiação para dedicar-se à defesa dos seus interesses”. Toda essa movimentação de trabalhadores de diversos ofícios fazia da sede do Círculo um local bastante relevante para a organização dos operários da Mooca.

O papel de abrigo societário aos militantes do período não foi, entretanto, a única forma de atuação do grupo. A mesma notícia informava que entre aquelas reuniões para constituir organizações de ofício, o CES Francisco Ferrer realizou, às oito

\footnotetext{
${ }^{34}$ A Lanterna, 24/02/1912.

35 BIONDI, Luigi. Classe e Nação: trabalhadores e socialistas italianos em São Paulo (1890-1920). Campinas-SP: Editora da Unicamp, 2011, p. 284-285.

36 Fanfulla, 10/03/1912.

37 Correio Paulistano, 17/05/1912.
} 
e meia da noite de 16 de março de 1912, no salão Leale Oberdan, uma festa de propaganda cujo programa era o seguinte:

(...) comedia em três atos de Ettore Dominici, La Legge del Cuore, e a farsa em um ato 'Os 2 conquistadores'. Por um companheiro será realizada uma conferência sobre o tema La donna e l'avvenire. A velada terminará com um baile familiar. $3^{8}$

Os temas teatrais não parecem representar, à primeira vista, uma ligação direta com as reivindicações do movimento operário. Todavia, não era algo de incomum que muitos grupos militantes tivessem que se contentar com peças e autores que apenas em parte servissem como instrumentos de conscientização dos operários. 39 Outras atividades, porém, ligavam-se mais diretamente aos ideais políticos da associação. A conferência que versou sobre a relação entre a mulher e o porvir talvez sirva como um bom exemplo, porque, muitas vezes, os conferencistas da associação lançaram a questão da mulher ao centro das discussões, passando por variações do tema tais como a família, mãe ou maternidade. Além disso, é preciso destacar que uma importante função no grupo cabia à operária e atriz amadora Trieste Amato, que era a encarregada das organizações dos eventos e, principalmente, ocupava o cargo de diretora do corpo cênico, e depois do grupo dramático, mantido pelo Círculo. 40

A escolha de representar a obra Os dois conquistadores, de autoria dos portugueses Joaquim Augusto de Oliveira e Jorge de Faria41, pode revelar uma tentativa de inserir-se de forma mais ampla entre a população do bairro, que era composta também por espanhóis e portugueses, além de indicar a presença de trabalhadores dessas nacionalidades no grupo. De toda forma, essas escolhas nos mostram que eram muitas as formas e as atividades que se empregavam para tentar

\footnotetext{
${ }^{38}$ A Lanterna, 16/03/1912.

39 TRENTO, Angelo. "Organização Operária e Organização do Tempo Livre entre os Imigrantes Italianos em São Paulo". In: CARNEIRO, Maria L. T. et. al. (org.), História do Trabalho e História das migrações: Trabalhadores Italianos e Sindicatos no Brasil (Séculos XIX e XX). São Paulo: Edusp: Fapesp, 2010, p. 242. 40 Esta indicação está em Fanfulla, 08/02/1913.

${ }^{41} \mathrm{Ver}<$ https://alpha.sib.uc.pt/?q=content/os-dois-conquistadores-cassoada-em-1-acto>. Acesso em: 9 mar. 2015.
} 
inserir-se entre as camadas populares e sensibilizar os trabalhadores para a sua realidade social.

Seguindo o seu caráter educativo, o CES Francisco Ferrer promovia aulas, palestras e conferências que tratavam de temas caros ao movimento operário. Quando ainda estava no bairro do Brás, o grupo ofereceu aos trabalhadores uma "lição de astronomia", apresentadas em duas terças-feiras à noite. É notável que os organizadores, para acompanhar a primeira lição de astronomia que se realizou em 12 de setembro de 1911, previssem a "comemoração da queda temporal do papa" ${ }^{2}$, fato este que amplia as utilizações das aulas, excedendo a difusão do conhecimento e alcançando o teor abertamente anticlericalista.

As palestras realizadas eram normalmente proferidas por nomes conhecidos no meio operário, como o de Scala, o de Leão Aymoré, este secretário da Escola Moderna, ligada aos anarquistas43, e Paolo Mazzoldi, socialista empregado como jornalista no Fanfulla, que certa vez discutiu o tema "Trabalho e Educação" na sede da rua da Mooca.44 Esses encontros reforçam a grande circulação de trabalhadores e de suas idéias entre os diversos grupos existentes pela cidade. Mas ao mesmo tempo ressaltam que o Círculo se mostrava aberto às diferentes correntes do movimento operário, servindo de ponto de apoio e encontro dos trabalhadores, reforçando assim um caráter mais ligado ao sindicalismo revolucionário. 45

\section{Um período de grande atividade}

O ano de 1912 foi marcado por grande atividade para o CES Francisco Ferrer. No início de maio, o grupo se dedicou a um dos eventos mais importantes - se não o mais importante - para as associações de trabalhadores. O Primeiro de Maio, como se

\footnotetext{
42 Fanfulla, 11/09/1911 e 18/09/1911.

43 A Lanterna, 09/07/1910.

${ }^{44}$ Fanfulla, 24/10/1910.

${ }^{45}$ Ver TOLEDO, Edilene. Travessias Revolucionárias: idéias e militantes sindicalistas em São Paulo e na Itália (1890-1945). Campinas-SP: Editora da Unicamp, 2004, p. 185 e 274-276.
} 
sabe, era uma data em que se atenuavam as divisões dentro do movimento operário, sendo um evento de caráter universal, que compreendia todos os grupos e ofícios. 46

As comemorações daquele ano tiveram início na noite de 30 de abril, com festas de propaganda realizadas por toda a cidade de São Paulo, com bailes, teatro e conferências sobre a importância da data, combinando assim o prazer da festa com o engajamento político. No dia seguinte, primeiro de maio, os trabalhadores se concentravam nas primeiras horas da manhã em frente à sede do CES Francisco Ferrer na Mooca para em seguida tomar as ruas. Às oito horas, com banda de música à frente - este elemento indispensável aos eventos do movimento operário, ao mesmo tempo anunciando e alinhando os trabalhadores que a seguiam47 -, partiram em direção ao largo da Concórdia, no Brás, onde participaram de um comício promovido pelos membros do Círculo e do Centro Socialista Internacional, grupo este de que fazia parte Giovanni Scala e que se concentrou no endereço do Círculo, na Mooca. ${ }^{48}$

Após os comícios no largo da Concórdia, os trabalhadores partiram em direção ao centro da cidade, mais especificamente à rua do Carmo, n. ${ }^{\circ} 39$, no salão Celso Garcia, de propriedade da Associação Auxiliadora das Classes Laboriosas, onde já estavam os sócios da União dos Canteiros. Segundo os relatos daquele dia, às onze horas da manhã, as atividades no salão foram interrompidas por uma melodia vinda de fora. "Era a coluna do Braz que acabava de chegar", ao som do “(...) Hino dos Trabalhadores, cantado na rua por centenas de vozes”. Um articulista d'A Lanterna tentava registrar a grande emoção causada pelos trabalhadores do Brás e da Mooca: "impossível seria descrever o entusiasmo desse momento em que os vivas confundiamse com as notas empolgantes do hino rebelde". Depois, todos tentavam se acomodar pelo salão. Por causa da grande quantidade de pessoas, muitos trabalhadores tiveram

\footnotetext{
${ }^{46}$ BATALHA, Claudio. "Cultura associativa no Rio de Janeiro da Primeira República". In: BATALHA, Claudio H. M. et. al. (Org.). Cultura de Classes: identidade e diversidade na formação do operariado. CampinasSP: Editora Unicamp, 2004, p. 105.

${ }^{47}$ HARDMAN, Francisco Foot. "Lyra da Lapa: acorde imperfeito menor". In: HARDMAN, Francisco Foot, Nem pátria, nem patrão: memória operária, cultura e literatura no Brasil. São Paulo: UNESP, 2002, p. 369. 48 A Lanterna, 06/05/1912. O Centro Socialista Internacional havia se extinguido dois anos antes, cabendo à Lega della Democrazia o papel de abrigo societário dos socialistas. Contudo, Giovanni Scala fez parte de ambas, o que sugere que ele e outros companheiros tenham utilizado o nome do Centro como forma de aglutinar os socialistas do bairro da Mooca e representar esta corrente no desfile. Ver BIONDI, Luigi. Classe e Nação: trabalhadores e socialistas italianos em São Paulo (1890-1920). CampinasSP: Editora da Unicamp, 2011, p. 292.
} 
de se colocar nos corredores, nas escadarias e na rua para ouvir aos diversos oradores. Ao meio-dia, para o encerramento, Edgard Leuenroth, em nome da União dos Canteiros, discursou sobre a necessidade de se tomar parte nas lutas, “(...) pois é ao povo que cabe a defesa dos seus interesses”. O evento no salão estava encerrado, o dia, não. E “(...) cantando em coro a 'internacional', o povo saiu para a rua, formando-se em uma compacta coluna, que percorreu o triangulo central e dissolveu-se na rua da Consolação".49

O mês de maio de 1912 foi, de fato, de muita atividade para o CES Francisco Ferrer. Poucos dias depois, uma comemoração à data de 13 de Maio foi marcada com uma palestra realizada na sede, falando “(...) pela ocasião diversos oradores em italiano e em português. A comemoração será pública”. $5^{\circ}$ Os trabalhadores negros tinham forte presença no bairro da Mooca, mas não há indícios de uma associação formada entre eles. Apesar de não podermos fazer nenhuma afirmação categórica, por causa da escassez de fontes a esse respeito, ao cruzarmos os indícios contidos na nota sobre a palestra, isto é, a comemoração do 13 de Maio, especificamente, e a apresentação das idéias nos idiomas italiano e português, surgem sinais, além da afirmação do internacionalismo, da presença de trabalhadores negros entre os associados do Círculo. ${ }^{1}$

Voltando agora às atividades, fechando aquele mês o grupo organizou conferências científicas, realizadas por uma “(...) conhecido orador”. ${ }^{2}$ Mas outras atividades importantes envolveram os membros do CES Francisco Ferrer, ainda que indiretamente. A União dos Sapateiros, cujo secretário era Francisco Calvo, encabeçou uma greve iniciada na fábrica Clark, na Mooca, onde trabalhava Calvo. Em seguida, os operários do ramo têxtil do bairro entraram em paralisação. A partir de então, cerca de

\footnotetext{
49 A Lanterna, 06/05/1912.

50 A Lanterna, 12/05/1912.

$51 \mathrm{O}$ associativismo negro era muito forte no bairro do Bexiga, mesmo que não restrito àquele local. Contudo, por toda a cidade se encontravam apenas sete sociedades compostas por negros exclusivamente, o que revela certa dificuldade em localizar esses grupos. Sobre o associativismo dos trabalhadores negros no bairro do Bexiga, ver SIQUEIRA, Uassyr. Entre sindicatos, clubes e botequins: identidades, associações e lazer dos trabalhadores paulistanos (1890-1920). Tese de doutorado. Unicamp. Campinas, 2008. Para uma listagem das associações compostas por trabalhadores negros, ver DOMINGUES, Petrônio. "Movimento Negro Brasileiro: alguns apontamentos históricos". Tempo. Niterói, v. 12 , n. 23, 2007, p. 103.

52 Correio Paulistano, 19/05/1912.
} 
dez mil trabalhadores entravam em greve pela cidade, exigindo aumento salarial, abolição de salário por peça e, sobretudo, a redução da jornada de trabalho para oito horas. Naquele ano, os sapateiros retornaram ao trabalho com vitória: aumento salarial de $10 \%$ e redução da jornada para oito horas e meia.53

Um fator que certamente contribuiu para a expansão da greve foi a prisão de Calvo, que às 10 horas da noite de 9 de maio, ainda no início das paralisações, “(...) foi inopinadamente agarrado no largo da sé por um desses tipos abjetos, excrecências do último estádio da degradação moral a que se dá o nome de espiões secretas”. O paradeiro de Calvo manteve-se desconhecido dos companheiros por mais de duas semanas. Somente no fim de maio, após ser levado secretamente a diversos postos policiais da cidade, sofrendo diversas torturas, o operário, depois de encapuzado e agredido, foi solto na várzea de Santo Amaro.54

Apesar do que ocorreu com Calvo, as atividades do CES Francisco Ferrer não cessaram. No início de junho, ao lado de diversas associações, o grupo participou ativamente da constituição da Liga Popular Contra a Carestia de Vida, cujo objetivo maior era conscientizar e reunir os trabalhadores contra a escassez, a miséria e as privações da “(...) atualmente desesperadora vida do pobre”.55 Reuniões foram realizadas em praticamente todos os bairros populares da capital. Uma das primeiras ocorreu no dia 15, no Cine São João, na Mooca, onde “(...) falarão diversos membros da Liga e outros oradores. Todos devem se esforçar para que essas reuniões sejam o mais concorridas [sic] possível”. 56

No dia 27 de junho, uma quinta-feira à noite, o Círculo realizou ainda uma sessão de propaganda “(...) na qual falarão diversos companheiros em português, espanhol e italiano”. Os idiomas escolhidos, mais uma vez, refletiam a composição mesma do bairro da Mooca, denotando o esforço por parte do grupo de ampliar a sua atuação junto à população ali residente - fato que é reforçado se levarmos em consideração que “(...) será franca a entrada para essa reunião”.57 Mas, além disso, os

\footnotetext{
53 BIONDI, Luigi. Classe e Nação: trabalhadores e socialistas italianos em São Paulo (1890-1920). Campinas-SP: Editora da Unicamp, 2011, p. 285; e Correio Paulistano, 19/05/1912.

54 A Lanterna, 25/05/1912.

55 A Lanterna, 15/06/1912 e 19/04/1913.

${ }^{56}$ A Lanterna, 09/06/1912.

57 A Lanterna, 22/06/1912.
} 
idiomas são um reforço da idéia de que o grupo era formado por pessoas dessas etnias, lembrando que Scala era italiano, e Calvo, espanhol.

No mês seguinte, na noite de sábado, 13, a reunião realizada com entrada franca foi dedicada a “(...) uma sessão de propaganda sobre o 14 de julho"58, aniversário da queda da Bastilha, um evento que as associações do movimento operário utilizavam largamente buscando evocar a “(...) Revolução Francesa como momento de nascimento da luta pela liberação do homem e a tarefa destinada ao movimento operário de continuá-la”.59

Em 12 de outubro, sábado à noite, no salão Celso Garcia, o CES Francisco Ferrer realizou uma festa em que “(...) serão representadas as seguintes peças: L'Ideale, de Pietro Gori, Triste Carnevale, e Um Hotel Modelo. L’Amore, será o tema da conferencia que desenvolverá um companheiro. A festa encerrar-se-á com um baile familiar". 60

Observando as informações sobre esta última festa, o repertório de peças teatrais apresentava títulos nos idiomas italiano e português, reforçando novamente o internacionalismo na composição e entre os valores do grupo. Em língua portuguesa, foi representada a obra Um Hotel Modelo, sobre a qual sabemos pouco além de que se tratava de uma comédia de autoria do português João Borges. ${ }^{61}$ Mas, uma vez mais, compunha o repertório uma obra de Pietro Gori, L'Ideale, um título que se remete à projeção “(...) das utopias libertárias”, uma sociedade ideal e livre, baseada “(...) na igualdade e ajuda mútua”. Todavia, é bastante relevante o fato de que constavam no programa, novamente, obras que não apresentavam um sentido estritamente político, como dramas românticos ou comédias. Sobre estes casos, lembremos aqui que as associações de caráter mais político utilizavam as obras com o sentido de levar à reflexão. E não podemos descartar a possibilidade de que os atores reinterpretavam o texto durante a atuação de forma a sensibilizar socialmente os espectadores. 62

\footnotetext{
58 A Lanterna, 13/07/1912.

59 BATALHA, Claudio H. M., "'Nós, Filhos da Revolução Francesa', a Imagem da Revolução no Movimento Operário Brasileiro no Início do Século XX". Revista Brasileira de História. São Paulo, v. 20, n.19, 1991, p. 241.

60 A Lanterna, 28/09/1912.

${ }^{61} \mathrm{Ver}<$ http://porbase.bnportugal.pt/>. Acesso em: 9 mar. 2015.

62 PRADO, Antônio A. et. al. (Org.), Contos Anarquistas: temas \& textos da prosa libertária no Brasil (18901935). São Paulo: Editora WMF Martins Fontes, 2011, p. XXXI, XXXII e XXXIII.
} 
Antes de prosseguirmos, é preciso notar que o dia da festa marcava a véspera do aniversário de morte de Francisco Ferrer y Guardia, conhecido pedagogo libertário espanhol, fuzilado em 13 de outubro de 1909, a quem o Círculo homenageou em sua nomenclatura. Mas, estranhamente, o programa não faz nenhuma referência à data. No ano anterior, o CES Francisco Ferrer comemorou o 13 de Outubro junto à "Loja Massonica "União Hespanhola" com uma conferência sobre "Os crimes do clericalismo"63, algo que se alinhava diretamente ao combate do pedagogo Ferrer frente ao predomínio do clericalismo nesse campo. Nos anos seguintes, contudo, a data de fuzilamento de Ferrer não foi mais incluída entre os eventos. Não dispomos de dados concretos que nos permitam construir uma hipótese sobre o fato. Contudo, não podemos descartar a possibilidade de que menções tenham sido feitas entre uma e outra atividade durante o evento de outubro de 1912. Além disso, o mote do anticlericalismo e as ações de cunho pedagógico - como as aulas científicas continuaram a ser promovidas.

De toda forma, uma importante comemoração, no mês seguinte, não foi esquecida. Os sócios do Círculo dedicaram-se à preparação de uma palestra para lembrar os cinco mártires de Chicago, data que, “(...) em rubros caracteres, registra-se na história da luta social como a pedra de toque do esforço empregado pelo proletariado universal para a conquista de sua emancipação integral”. No sábado, dia 9, às sete e meia da noite, realizou-se uma “sessão pública de propaganda”, “(...) para comemorar o 11 de Novembro (...). Falarão diversos companheiros”. 64

No fim de dezembro de 1912, o CES Francisco Ferrer promoveu uma reunião para comemorar o Ano Novo. Desta vez, contudo, não era um evento aberto a todos os interessados, mas somente aos sócios e familiares. Um orador do grupo fez uma conferência sobre o tema "A Família"65, algo que, como já vimos, se colocava frontalmente contra às concepções burguesa e clerical. Mas também, ao insistir na importância do núcleo familiar buscava-se a construção de uma rede de fundamental importância para a sobrevivência dos trabalhadores, que podia lhes garantir inserção no mercado de trabalho, solidariedade em tempos difíceis, a difusão da necessidade de

\footnotetext{
63 Fanfulla, 09/10/1911.

${ }^{64}$ A Lanterna, 09/11/1912.

65 Fanfulla, 30/12/1912.
} 
conquista e defesa de direitos obtidos a muito custo e, sobretudo, de constituição de organizações políticas e sindicais. ${ }^{66} \mathrm{Na}$ verdade, a questão da família - mesmo na constante indicação do baile familiar - esteve presente em praticamente todos os eventos do CES Francisco Ferrer, ora dividindo, ora cedendo espaço para outro tema bastante em foco naquele período, que era a questão da miséria.

Em fevereiro de 1913, realizou-se uma festa em que se mesclavam o tema da miséria com outras diversões, como o baile familiar, conforme podemos ver no programa.

Primeira parte - Será representado pelo grupo filodramático do Círculo, dirigido pela senhora Trieste Amato, o grande drama em três atos de Enrico Ibsen: 'Gli Spettri'. Personagens: A sra. Alving, viúva do capitão e camareiro Alving, senhorita Trieste Amato; Osvaldo Alving, pintor, Oberdan Rossi; Pastor Manders, Ticiano Gennaro; Engstrand, carpinteiro, Tommaso Camilli; Reguia Engstrand, empregada doméstica da Sra. Alving, senhorita Amalia Italia.

Segunda parte - Conferência sobre o tema - 'A miséria'.

Terceira parte - 'Qualcuno guastò la festa!', obra social em 1 ato de M. Marsolleau. Personagens: Agricultor e operário, Tomaso Camilli; Banqueiro, Amore Cozzolino; Deputado, Giacomo Gerardini; Duquesa, senhorita Trieste Amato; Cortesã, senhorita Amalia Italy; Juiz, Emilio Mingarelli; General, Antonio de Santis; Bispo, Vicenzo Falotico. No final do espetáculo será sorteada uma bela pintura em óleo do pintor espanhol Vidal.

Quarta parte - Baile familiar.

Pelo que revelaram os resultados da festa, Scala, que realizou a conferência, “(...) foi interrompido várias vezes por aplausos repetidos". ${ }^{67}$ Ao tratar da miséria, naquele período, o grupo demonstrava estar atento às preocupações dos trabalhadores. A conferência encontrava-se em acordo com as idéias da Liga Contra a Carestia de Vida. Do mesmo modo podemos entender a utilização na festa do drama de Ibsen, Spettri, cujo mote era o da “(...) fatalidade da condição humana agindo sobre os

\footnotetext{
66 Mike Savage, "Classe e História do trabalho". In: Claudio H. M. Batalha et. al. (Org.), Cultura de Classes: identidade e diversidade na formação do operariado. Campinas-SP: Editora Unicamp, 2004, p. 42. 67 Fanfulla, 08/02/1913 e 10/02/1913.
} 
personagens"68, e da obra Qualcuno guastò la festa (alguém estragou a festa - em tradução livre), de Louis Marsoleau, que tratava em tom jocoso dos hábitos do clero em relação às ceias ${ }^{69}$, aliando o anticlericalismo à realidade dos trabalhadores.

Essas ligações entre os temas apresentados e as participações do grupo nas ações da Liga Contra a Carestia reforçam a idéia da utilização das festas para um sentido bastante prático de inserção dos trabalhadores nos atos do movimento operário. De fato, esses mesmos valores foram reforçados pelo CES Francisco Ferrer pouco menos de dois meses depois. Em 1 de abril de 1913, uma terça-feira, às sete e meia da noite, o grupo promoveu a “(...) segunda lição de história natural”70, um tema que que se alinhava às concepções anticlericais, mantendo acesa a crítica à educação religiosa - e burguesa. E poucos dias depois, a Liga Contra a Carestia de Vida, na qual junto com os outros grupos o Círculo tinha a função de preparar os comícios e de levar bandeiras e cartazes aos eventos, retomou as atividades, realizando diversos encontros e combatendo a “(...) exploração dos condecorados ladrões de casaca”71.

Em junho de 1913, os membros do CES Francisco Ferrer estavam presentes nas reuniões de propaganda promovidas pelo Sindicato de Ofícios Vários. Calvo e Scala realizaram discussões sobre a “(...) a utilidade da organização”, que “(...) ficou bem patenteada pelos oradores, demonstrando-se que é ela o único meio com que contam os operários para reivindicar os direitos conspurcados”. Poucos dias depois, o Ofícios Vários promoveu na sede do Círculo a “(...) segunda reunião de propaganda”, em que, “(...) apesar da concorrência não ser numerosa, reinou bastante entusiasmo, tendo sido feita uma coleta pró-Jabert”. ${ }^{72}$

A necessidade de organização explicitada nas palestras continuou presente nos esforços do Círculo. Em 19 de julho, no salão Celso Garcia, entre uma e outra apresentação teatral, Scala discursou sobre "a necessidade de um ideal no movimento operário”. O programa da festa, incluindo a conferência, mantinha-se praticamente

\footnotetext{
68 SILVA, Jane P. Ibsen no Brasil: historiografia, seleção de textos críticos e catálogo bibliográfico. Dissertação de Mestrado. Universidade de São Paulo, USP: São Paulo, 2007, p. 68.

${ }^{69}$ VARGAS, Maria T. (Coord.), Teatro operário na cidade de São Paulo. São Paulo; Secretaria Municipal de Cultura, Departamento de Informação e Documentação Artísticas, Centro de Pesquisa de Arte Brasileira, 1980, p. 70.

70 Fanfulla, 31/03/1913.

${ }^{71}$ A Lanterna, 19/04/1913

${ }^{72}$ A Lanterna, 21/06/1913.
} 
igual aos anteriores, combinando práticas tais como bailes e quermesses com temas mais identificados com valores e interesses de classe. Os participantes da festa assistiram ao drama de autoria de Roberto Bracco, Il diritto di vivere,

(...) sob a direção da brava atriz senhora Trieste Amato, que desempenhou de maneira irretocável o papel de Maddalena; também as senhoras N. N. e A. Italy foram uma perfeita Brigida e a outra uma Nannina impecável; os senhores O. Rossi, D. Negrini, J. Amato, A. Zoccolino, G. Giardini, V. Ambrosio, S. Papa, N. N., F. Mingarelli, V. Amadio, G. Nicolai, U. Guazzini, U. G. e A. Giannicelli desempenharam seus papéis muito bem.

Em seguida, o monólogo intitulado Una Madre, de autoria de E. Roland, foi interpretado por Trieste Amato e, depois, foi posta em cena a comédia "Se fra un'ora?", que "(...) divertiu imensamente os espectadores que se acabaram em riso". O aguardado baile, e "(...) as danças muito animadas, que duraram até a madrugada de ontem, deram fim à bela festa”.73

\section{O declínio do Círculo}

Apesar dos esforços do CES Francisco Ferrer e de outros grupos, o ano de 1913 foi marcado pelo início de uma fase de desorganização que, aliada à situação de crise econômica, desestruturação do mercado de trabalho e crescente desemprego, faria com que o movimento sindical entrasse novamente em declínio, enfraquecendo, ao mesmo tempo, as associações que dependiam diretamente da contribuição regular dos sócios para continuar com suas atividades.74 Muito por isso, durante quatro meses não houve notícias de atividades envolvendo o Círculo.

Em outubro, Calvo dirigiu-se à cidade de Bragança, no interior de São Paulo, para participar de um comício, em que “(...) fez um caloroso apelo aos operários para se instruírem, pois da instrução depende em grande parte a emancipação proletária”.75

\footnotetext{
73 Fanfulla, 21/07/1913.

74 BIONDI, Luigi. Classe e Nação: trabalhadores e socialistas italianos em São Paulo (1890-1920). Campinas-SP: Editora da Unicamp, 2011, p. 284-305.

${ }^{75}$ A Lanterna, 16/10/1913
} 
Mas foi somente em 15 de novembro que o Círculo mostrou alguma atividade. O programa anunciava:

$1^{\mathrm{o}}$ - Gente onesta, importante drama em 3 atos, de Pedro Gori; $2^{\mathrm{o}}$ Conferência sobre o tema La famiglia; $3^{0}$ - Uma engraçada comédia; $4^{0}$ Quermesse e baile familiar. ${ }^{76}$

A partir de então, as atividades do Círculo tornam-se mais rarefeitas. Sete meses se passaram até que a associação reaparecesse, em junho de 1914, subscrevendo o manifesto do recém surgido Comitê Pelas Vítimas Políticas da Reação Italiana, este que tinha por objetivo principal a ajuda aos “(...) subversivos da Itália”. Ao CES Francisco Ferrer cabia propagar no bairro da Mooca a necessidade de que os operários, “(...) num generoso movimento, contribuam com a sua quota de solidariedade”.77

Em julho de 1914, teve lugar no salão Leale Oberdan, no Brás, a última festa de propaganda que o CES Francisco Ferrer realizou. O programa, mantendo a mesma estrutura dos anos anteriores, era o seguinte:

$1^{\mathrm{O}}$ - Maternitá - drama em 4 atos de Roberto Bracco, representado pelo grupo dramático do Círculo; $2^{\circ}$ - Conferencia; $3^{\circ}$ - Representação de uma comedia; $4^{\mathrm{o}}$ - Baile familiar. ${ }^{78}$

A pequena nota destinada à festa, último registro de um evento deste tipo envolvendo o Círculo, e a ausência da divulgação dos resultados, indicam que o grupo enfrentava dificuldades. No mesmo mês, Calvo passou a integrar também o Grupo Dramático Libertário, do qual faziam parte Antonio Nalepinski, Virgílio Fidalgo e José Romero79, possivelmente buscando outros lugares onde pudesse atuar.

Apenas em maio de 1915, dez meses depois da pequena festa, o Círculo reaparece integrando a Comissão Internacionalista Contra a Guerra “(...) que agrupa as entidades da vanguarda do elemento avançado”. Nos comícios, os membros do CES Francisco Ferrer tiveram como companhia diversos militantes do movimento operário como

\footnotetext{
76 A Lanterna, 08/11/1913.

77 A Lanterna, 20/06/1914.

78 A Lanterna, 11/07/1914.

${ }^{79}$ A Lanterna, 18/07/1914.
} 
Edgard Leuenroth, Vittorio Buttis, Passos Cunha e Ambrosio Chiodi. ${ }^{80}$ Entretanto, a participação na Comissão foi a última atividade do CES Francisco Ferrer, provavelmente devido às dificuldades que vinham se desenrolando desde 1913 combinadas com a apatia que reinou sobre o movimento sindical a partir do fim de 1914. ${ }^{81}$ Ainda em 1915, um de seus principais animadores, Angelo Scala, voltou à Itália para lutar na Primeira Guerra, retornando a São Paulo somente em 1919. ${ }^{82}$

Em 1915, o Círculo de Estudos Sociais Francisco Ferrer deixou de atuar.

\section{Considerações finais}

O estudo das experiências do Círculo de Estudos Sociais Francisco Ferrer, abordadas aqui de forma a manter a ordem cronológica da trajetória do grupo, permite tornar evidente as formas pelas quais as atividades políticas e de lazer podiam se combinar na atuação de uma associação de trabalhadores. Obviamente, não se pretende que as práticas deste grupo sejam tomadas como exemplo genérico de todas as sociedades do período. Todavia, elas certamente refletem os modos de atuação, em uma ou outra medida, de muitos grupos operários, e nos ajudam a entender melhor como se dava a dinâmica associativa e os esforços de organização dos trabalhadores.

Nas ações do CES Francisco Ferrer, é possível observar uma multiplicidade de atividades que perpassavam a difusão de valores classistas, a organização política, o aprofundamento cultural e elementos destinados à diversão, como as festas e os bailes, revelando ainda o esforço do grupo de adentrar nos meios populares. A atuação do Círculo se revelou ainda mais complexa quando levamos em consideração as diversas conexões entre associações e trabalhadores, aglutinando diferentes experiências políticas e de associativismo. Assim, as experiências que observamos com o Círculo parecem afastar qualquer prerrogativa de homogeneidade que se possa querer lançar sobre o movimento operário da cidade de São Paulo.

\footnotetext{
80 A Lanterna, 01/05/1915.

81 BIONDI, Luigi. Classe e Nação: trabalhadores e socialistas italianos em São Paulo (1890-1920). Campinas-SP: Editora da Unicamp, 2011, p. 285.

82 TOLEDO, Edilene. Travessias Revolucionárias: idéias e militantes sindicalistas em São Paulo e na Itália (1890-1945). Campinas-SP: Editora da Unicamp, 2004, p. 376.
} 
Finalmente, a atuação do CES Francisco Ferrer na sensibilização dos trabalhadores, empregando diversas atividades, pode nos servir de base para observar as formas de atuação das associações de trabalhadores, incluídas aí as recreativas, na busca pela organização e tomada de consciência, reforçando ainda a importância do estudo dos momentos de lazer para o entendimento do processo formativo da classe operária.

\section{Referências bibliográficas}

BATALHA, Claudio H. M. “Nós, Filhos da Revolução Francesa', a Imagem da Revolução no Movimento Operário Brasileiro no Início do Século XX”. Revista Brasileira de História. São Paulo, v. 20, n.19, pp. 233-249, 1991.

BATALHA, Claudio H. M. "Cultura associativa no Rio de Janeiro da Primeira República”. In: BATALHA, Claudio H. M. et. al. (Org.). Cultura de Classes: identidade e diversidade na formação do operariado. Campinas, SP: Editora Unicamp, 2004, pp. 95-120.

BIONDI, Luigi. Classe e Nação: trabalhadores e socialistas italianos em São Paulo (1890-1920). Campinas-SP: Editora da Unicamp, 2011.

BIONDI, Luigi. Entre associações étnicas e de classe: os processos de organização política e sindical dos trabalhadores italianos na cidade de São Paulo (189o-1920). Tese de doutorado. Universidade Estadual de Campinas, Unicamp: Campinas-SP: 2002.

CABRAL, Michelle N. Teatro Anarquista, Futebol e Propaganda: tensões e contradições no âmbito do lazer. Dissertação de Mestrado. Universidade Federal do Rio de Janeiro, UFRJ: Rio de Janeiro, 2008.

DOMINGUES, Petrônio J. "Movimento Negro Brasileiro: alguns apontamentos históricos”. Tempo [online]. Niterói, v. 12, n. 23, pp. 100-122, 2007

HALL, Michael M. "Imigrantes na cidade de São Paulo". In: PORTA, Paula (org.). História da Cidade de São Paulo: a cidade na primeira metade do século XX. (v. 3). São Paulo: Paz e Terra, 2004. pp. 121-151. 
HALL, Michael M. “O Movimento Operário na Cidade de São Paulo: 1890-1954”. In: PORTA, Paula (org.). História da Cidade de São Paulo: a cidade na primeira metade do século XX. (v. 3). São Paulo: Paz e Terra, 2004. pp. 259-289.

HALL, Michael M.; PINHEIRO, Paulo. (Org.). A Classe Operária no Brasil. 1899-1930. Documentos. Volume I - O Movimento Operário. Alfa-Ômega: São Paulo, 1979.

HARDMAN, Francisco F. "Lyra da Lapa: acorde imperfeito menor”. In: HARDMAN, Francisco F. Nem pátria, nem patrão: memória operária, cultura e literatura no Brasil. São Paulo: UNESP, 2002. pp. 367-376.

HOBSBAWM, Eric J. “O Debate Sobre a Aristocracia Operária”. In: HOBSBAWM, Eric J. Mundos do Trabalho: novos estudos sobre história operária. Rio de Janeiro: Paz e Terra, 2000. pp. 305-322.

PRADO, Antônio A. et. al. (Org.). Contos Anarquistas: temas \& textos da prosa libertária no Brasil (1890-1935). São Paulo: Editora WMF Martins Fontes, 2011. PRADO, Antônio A. Trincheira, Palco e Letras. Crítica, literatura e utopia no Brasil. São Paulo: Cosac \& Naify, 2004.

SAVAGE, Mike. "Classe e História do trabalho”. In: BATALHA, Claudio H. M. et. al. (Org.). Cultura de Classes: identidade e diversidade na formação do operariado. Campinas-SP: Editora Unicamp, 2004. pp. 25-48.

SILVA, Jane P. Ibsen no Brasil: historiografia, seleção de textos críticos e catálogo bibliográfico. Dissertação de Mestrado. Universidade de São Paulo, USP: São Paulo, 2007.

SIQUEIRA, Uassyr de. Entre sindicatos, clubes e botequins: identidades, associações e lazer dos trabalhadores paulistanos (1890-1920). Tese de doutorado. Unicamp. Campinas, 2008.

THOMPSON, Edward P. A Formação da Classe Operária Inglesa. v. 2. A maldição de Adão. Rio de Janeiro: Paz e Terra, 1987.

TOLEDO, Edilene. "Imigração, Sindicalismo Revolucionário e Fascismo na Trajetória do Militante Italiano Edmondo Rossoni”. Cadernos AEL, Campinas/IFCH/AEL, v. 15, n. 27, 2009.

TOLEDO, Edilene. “'Para a união do proletariado brasileiro': a Confederação Operária Brasileira, o sindicalismo e a defesa da autonomia dos trabalhadores no Brasil da 
Primeira República”. Perseu: História, Memória e Política, São Paulo, v. 7, pp. 10-31, 2013.

TOLEDO, Edilene. Travessias Revolucionárias: idéias e militantes sindicalistas em São Paulo e na Itália (1890-1945). Campinas-SP: Editora da Unicamp, 2004.

TRENTO, Angelo. "Organização Operária e Organização do Tempo Livre entre os Imigrantes Italianos em São Paulo”. In: CARNEIRO, Maria L. T. et. al. (org.). História do Trabalho e História das migrações: Trabalhadores Italianos e Sindicatos no Brasil (Séculos XIX e XX). São Paulo: Edusp: Fapesp, 2010. pp. 233-266.

VARGAS, Maria T. (Coord.). Teatro operário na cidade de São Paulo. São Paulo; Secretaria Municipal de Cultura, Departamento de Informação e Documentação Artísticas, Centro de Pesquisa de Arte Brasileira, 1980. 